\title{
A Keynesian (demand reduction) approach to the opioid epidemic
}

\author{
Heath McAnally*,1,2 \\ ${ }^{1}$ Northern Anesthesia \& Pain Medicine, LLC, Alaska 99577, USA \\ ${ }^{2}$ Department of Anesthesia \& Pain Medicine, University of Washington, Washington, DC 98195, USA \\ *Author for correspondence: northernpainmedicine@gmail.com
}

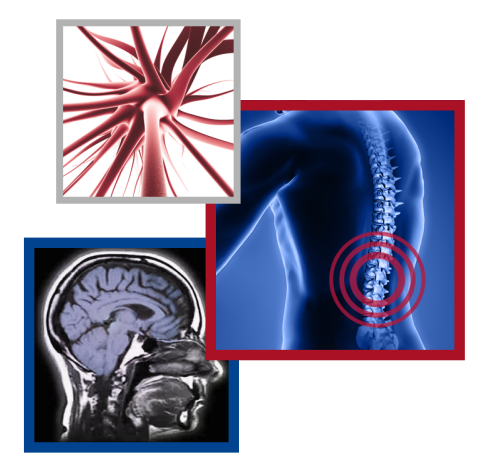

First draft submitted: 23 January 2017; Accepted for publication: 14 March 2018; Published online: 3 May 2018

Keywords: behavioral immunity • biopsychosocial • comfort $\bullet$ demand reduction $\bullet$ dependence $\bullet$ epidemic $\bullet$ opioid

America's opioid problem needs no introduction; it is almost impossible to escape media (or medical) coverage of the subject in this country. Further descriptive statistics are hardly necessary. More analytical epidemiology establishing causal factors with greater confidence is welcome but not likely to shed greater light on the subject. Although pain complaints ostensibly mediate opioid prescription, large-scale surveys such as the US National Epidemiologic Survey on Alcohol and Related Conditions and several other huge investigations [1] have shown that the most robust and relevant predictor variables for dependence are psychosocial ones, including pre-existing substance abuse, anxiety, post-traumatic stress disorder, various personality disorders - among others. We also know that factors such as decreased resilience, poor self-efficacy and external locus of control are integral to both the underlying psychological diatheses and the escape of chemical coping $[2,3]$.

\section{Demand reduction through conferring behavioral immunity}

The question is, what are we going to do about it? Most attention has focused upon alteration of agent virulence (opioid abuse deterrence) or attenuation of vector transmission (reduce prescription). However, while certainly worthwhile aims, ultimately these efforts will prove ineffectual without addressing the key component of this (and every) epidemic - the host [1]. Abuse deterrence mechanisms can be circumvented; ironically OxyContin ${ }^{\circledR}$ (Purdue Pharma, CT, USA) touted by its manufacturer as conferring markedly decreased addictive potential is now widely credited with the Appalachian genesis of this crisis. Restriction of supply at either production or prescription levels has the potential to lead to shift in drug of choice - witness the grim upsurge in heroin morbidity and mortality or synthesis of new illicits. Intervening upon the unique proclivity of the host to desire and pursue the agent is ultimately the only rational strategy in this war. After all, epidemics generally end either when the agent destroys the host population, or when a sufficient proportion of the populace develops immunity to the agent. Cultivation of what the psychologists call 'behavioral immunity' is our best if not only option.

\section{Demand reduction through education}

Supply and demand construct provides another perspective essentially illustrating the same concepts. Reducing consumption of a commodity is certainly achievable by supply restriction; however, in this situation for numerous reasons, supply restriction can and will only go so far as discussed above. Reducing demand is far more intelligent and ultimately efficacious. Establish population-level shunning of a product and the market disappears. Easier said than done when the product is perceived as essential to life or wellbeing. And that is where our job as physicians in educating (harms instruction, analgesia/anesthesia expectation recalibration and motivational enhancement) as well as behavior modification coaching becomes intensive.

Telling your teenagers in the midst of their complex developmental challenges and flux not to use drugs is rarely a sufficient strategy. We have to provide a nurturing, validating and strengthening environment for the development of our children's mettle/moral fiber that precludes any thought - let alone inclination - toward errantly and tragically trying to find security and significance in substances. It does not necessarily take a village. It does take focused, consistent and loving edification though. And while these are not our children we are dealing with here, 
in the same manner it takes time and effort to cultivate behavioral immunity among our patients. It does not work to just tell them not to use opioids, wean them off/refuse to prescribe and/or refer them out.

We need to reduce demand by fostering aversion based on fully-informed risk: benefit ratio analysis. We need to reduce demand by educating that pain is the most important protective sense an organism possesses, and is not something to simply be masked - its message is to be analyzed and acted upon by lifestyle change. The often shrouded underlying milieu of depression, anxiety, PTSD - among others. that motivates the majority of opioid dependence needs to be addressed and worked through. If we are not allowed access to those topics by guarded patients, at the very least simple education and intervention upon pain catastrophizing may yield great benefit $[4,5]$. Attenuating the emotion of fear attached to the sensation/perception of pain can sometimes be the most effective therapy we can provide.

\section{Demand reduction through addressing the underlying needs}

In nearly 20 years of medicine, I do not recall encountering demands for specific antihypertensives ('it has to be lisinopril') or early refill request for metformin - among others. The fact that we are not presented with these demands highlight the keyword in the sentence above: '... easier said than done when the product is perceived as essential to life or wellbeing'. Ironically, the sequelae of untreated hypertension, diabetes, hypothyroidism - among others. actually do pose very real threat to life, and and yet they are often not perceived as worthy of attention or lifestyle modification efforts. We demand what we think we need. Outside of the context of 'comfort drugs' (opioids, sedative-hypnotics, etc.) the only example in medicine of such product-specific demand I can recall from my own experience is a parent insisting on antibiotics for their child's viral upper respiratory infection. They are motivated by nothing less sacrosanct than perception of mortal danger to her offspring and the desperation to intervene on that perception.

What is it about the comfort provided by opioids that is perceived as essential? Given the vanishingly rare visual analog scale ratings of $0,1,2$ - among others. by chronic opioid users it is unlikely to be effective analgesia. The pain is still there, along with the associated and perhaps underlying emotional distress. But there is comfort of some sort attained by the use of opioids that the dependent individual just can not live without. And that comfort must rank higher on the individual's importance scale than health, or our general medical care would be directed to us by patients just as their analgesic orders are. Or perhaps we would go out of business altogether because chronic disease would be eliminated by wise and moderate choices of diet, exercise, toxin avoidance, psychological and relational and spiritual wellness - among others.

We need to reduce, or shift demand by providing a better product to the marketplace. Not more or different pharmacotherapeutics. We need, as the National Pain Strategy [6] has called for - a comprehensive and truly biopsychosocial-spiritual approach to overcoming and preventing chronic pain.

\section{Financial \& competing interests disclosure}

The author has no relevant affiliations or financial involvement with any organization or entity with a financial interest in or financial conflict with the subject matter or materials discussed in the manuscript. This includes employment, consultancies, honoraria, stock ownership or options, expert testimony, grants or patents received or pending, or royalties.

No writing assistance was utilized in the production of this manuscript.

\section{References}

1. McAnally HB. Opioid Dependence: a Clinical and Epidemiologic Approach. Springer, NY, USA (2017).

2. Joe GW, Simpson DD, Broome KM. Retention and patient engagement models for different treatment modalities in DATOS. Drug Alcohol Depend. 57(2), 113-25 (1999).

3. Flynn PM, Joe GW, Broome KM, Simpson DD, Brown BS. Recovery from opioid addiction in DATOS. J. Subst. Abus. Treat. 25(3), 177-186 (2003).

4. Sharifzadeh Y, Kao MC, Sturgeon JA, Rico TJ, Mackey S, Darnall BD. Pain catastrophizing moderates relationships between pain intensity and opioid prescription: nonlinear sex differences revealed using a learning health system. Anesthesiology 127(1), 136-146 (2017).

5. Darnall BD, Sturgeon JA, Kao MC, Hah JM, Mackey SC. From catastrophizing to recovery: a pilot study of a single-session treatment for pain catastrophizing. J. Pain Res. 7, 219-26 (2014).

6. Interagency Pain Research Coordinating Committee. National Pain Strategy: A Comprehensive Population Health-Level Strategy for Pain. NIH (2016). https://iprcc.nih.gov/sites/default/files/HHSNational_Pain_Strategy_508C.pdf 